\title{
SISTEM INFORMASI ALAT DAN MESIN PERTANIAN BERBASIS APLIKASI ANDROID DI KECAMATAN PARIAMAN UTARA KOTA PARIAMAN
}

\author{
Saddam Pebrianto ${ }^{1}$, Andasuryani ${ }^{2}$, dan Khandra Fahmy ${ }^{2}$ \\ ${ }^{1}$ Mahasiswa S2 Program Magister Teknik Pertanian, Kampus Limau Manis-Padang 25163 \\ ${ }^{2}$ Dosen Fakultas Teknologi Pertanian, Kampus Limau Manis-Padang 25163 \\ Email: saddampebrianto@gmail.com
}

\begin{abstract}
ABSTRAK
Fenomena ketidakmerataan distribusi alat dan mesin pertanian (aslintan), penurunan produksi padi dan menurunnya luas lahan sawah karena meningkatnya laju alih fungsi lahan yang terjadi di Kota Pariaman merupakan suatu persoalan yang sangat serius untuk ditangani pada saat ini (Putri et al., 2019). Permasalahan tersebut bisa diatasi dengan menerapkan suatu sistem informasi alsintan dan lahan sawah yang terpadu berbasis digital (android) dalam bentuk tampilan database dan peta. Pesatnya Perkembangan penggunaan smartphone berbasis android pada saat ini khususnya petani akan membuka peluang untuk mengembangkan sistem informasi di bidang pertanian dalam bentuk aplikasi android. Berdasarkan data StatCounter (2019), penggunaan smartphone dengan sistem operasi android di Indonesia mencapai $84,99 \%$ dari 355,5 juta pengguna telepon genggam. Penelitian ini memanfaatkan teknologi digital untuk pengembangan suatu sistem informasi alsintan dalam bentuk aplikasi berbasis android di Kecamatan Pariaman Utara Kota Pariaman. Keluaran dari penelitian ini berupa aplikasi android yang dinamakan SINTAN PARUT (Sistem Informasi Alsintan Pariaman Utara). Aplikasi SINTAN PARUT dapat dioperasikan pada android API 18 (Jelly Bean) sampai dengan android API 28 (Pie) serta bisa diakses secara mobile dan online. Aplikasi ini menampilkan data perhitungan kebutuhan ideal alsintan di Kecamatan Pariaman Utara. Dari hasil pengolahan data menunjukkan bahwa distribusi khusus alsintan pengolahan tanah dari 17 Desa terdapat 41,18\% mengalami kekurangan alsintan, sedangkan 41,18\% mengalami kelebihan alsintan dan hanya $17,64 \%$ memiliki kebutuhan alsintan yang ideal. Selanjutnya untuk alsintan pascapanen dari 17 Desa terdapat 29,42 \% mengalami kekurangan alsintan, sedangkan 17,64\% mengalami kelebihan alsintan dan 52,94\% memiliki kebutuhan alsintan yang ideal.

Kata kunci - alih fungsi lahan; android; distribusi alsintan; sistem informasi
\end{abstract}

\section{PENDAHULUAN}

Kota Pariaman memiliki lahan sawah sebesar 1.785 ha dengan produksi padi tahun 2018 adalah 35.850 ton atau mengalami penurunan sebesar 7,13\% dibandingkan dengan tahun 2017 yang produksinya sebesar 41.834 ton. Penurunan ini salah satunya disebabkan oleh berkurangnya lahan sawah yang diairi dengan sistem irigasi dari 1.923 ha pada tahun 2017 menjadi 1.383 ha pada tahun 2018 (BPS Kota Pariaman, 2019).

Untuk mendukung peningkatan produksi padi di Kota Pariaman, petani sudah menggunakan alat mesin pertanian (alsintan) seperti alsintan pengolahan tanah (traktor roda dua), alsintan penanaman, alsintan pemeliharaan, alsintan pemanenan dan alsintan pascapanen. Jumlah traktor roda dua di Kota Pariaman tercatat sejumlah 131 unit (BPS Provinsi Sumater Barat, 2018).

Jumlah traktor roda dua yang ada di Kota Pariaman berlebih, karena secara teknis untuk 1 unit traktor roda dua dalam satu musim tanam memiliki kapasitas kerja sebesar 20 - 30 hektar (Jamalus, 2016). Akan tetapi, penyebaran penggunaan traktor roda dua yang belum merata mengakibatkan tidak efektif dan efisiennya penggunaan traktor roda dua tersebut. Penyebaran traktor roda dua yang tidak merata tersebut dibuktikan oleh penelitian Fandra (2018), bahwa jumlah traktor roda dua yang paling banyak di Kota Pariaman berada di Kecamatan Pariaman Selatan sejumlah 70 unit, sedangkan areal lahan sawah paling luas berada di Kecamatan Pariaman Utara.

Disamping persoalan di atas, Kota Pariaman juga mengalami besarnya laju alih fungsi lahan. Khususnya alih fungsi lahan pertanian yang produktif untuk dijadikan wilayah permukiman, pertokoan, industri maupun peruntukan lainnya diluar pertanian. Putri et al. (2019) menyatakan bahwa pada tahun 2018 di Kota Pariaman lahan pertanian yang sudah dialihfungsikan mencapai 59,81 ha atau $3,25 \%$ dari total luas lahan pertanian. 
Fenomena penurunan produksi padi, ketidakmerataan distribusi aslintan dan menurunnya luas lahan sawah karena meningkatnya laju alih fungsi lahan yang terjadi di Kota Pariaman merupakan suatu persoalan yang sangat serius untuk ditangani pada saat ini. Permasalahan tersebut bisa ditangani dengan menerapkan suatu sistem informasi alsintan dan lahan sawah yang terpadu berbasis digital (android) dalam bentuk tampilan database dan peta. Pesatnya Perkembangan penggunaan smartphone berbasis android pada saat ini khususnya petani akan membuka peluang untuk mengembangkan sistem informasi di bidang pertanian dalam bentuk aplikasi android. Berdasarkan data StatCounter (2019), penggunaan smartphone dengan sistem operasi android di Indonesia mencapai 84,99\% dari 355,5 juta pengguna telepon genggam. Sistem informasi tersebut bisa digunakan untuk menentukan arah kebijakan dalam pendistribusian alsintan bantuan dari pemerintah pada masa yang akan datang sehingga dapat memudahkan stakeholder, petani dan masyarakat untuk dapat mengakses data dan kebutuhan alsintan secara cepat, efektif, dan efisien.

\section{METODOLOGI PENELITIAN}

Penelitian ini dilakukan di Kecamatan Pariaman Utara Kota Pariaman. Pengolahan data dilakukan di Laboratorium Sistem Manajemen Pertanian dan Informasi Geografis dan di Laboratorium Teknik Sumber Daya Lahan dan Air, Jurusan Teknik Pertanian, Fakultas Teknologi Pertanian Universitas Andalas Padang yang dilaksanakan pada bulan Oktober sampai dengan Desember 2019.

Alat yang digunakan dalam penelitian ini adalah seperangkat komputer untuk menjalankan program Sistem Operasi Linux Mint 19.1, ArcGIS 10..4.1, Microsoft Word 2013, Microsoft Visio 2013, IDE Android Studio, SDK (Software Dvelopment Kit), JDK (Java Developer's Kit), Coreldraw 2017, Global Positioning System (GPS), kamera digital, memory card dan seperangkat alat tulis.

Penelitian ini dilakukan dengan beberapa tahapan yaitu: 1) mengumpulkan data sekunder dari instansi/dinas terkait untuk data alsintan, peta dan data luasan sawah di Kecamatan Padang Utara; 2) mengolah data alsintan, peta dan dan data lahan sawah menggunakan ArcGIS; 3) dilakukan survei ke lokasi penelitian untuk melakukan Ground Check Point (GPC); 4) dilakukan verifikasi terhadap data yang didapatkan dari instansi/dinas dengan data hasil GPC yang dihasilkan dari lokasi penelitian; 5) perhitungan kebutuhan alsintan dengan persamaan (1) dan (2); 6) hasil dari pengolahan data alsintan dan data luasan sawah dilanjutkan pada proses perancangan sistem informasi berbasis aplikasi android sesuai dengan prosedur yang telah diteliti oleh Indriawardhana (2019); 7) dilakukan pengujian terhadap aplikasi android yang sudah selesai dirancang; 8) dilakukan proses keputusan apakah aplikasi sudah berfungsi dengan baik atau tidak (apabila aplikasi tidak berfungsi dengan baik maka akan kembali kepada tahapan kelima, sedangkan apabila aplikasi berfungi dengan baik maka proses akan dilanjutkan pada tahapan berikutnya); dan 9) setelah proses keputusan bisa dilanjutkan maka sistem informasi alsintan berbasis aplikasi android sudah selesai dan siap untuk digunakan.

Jumlah Kebutuhan Alsintan Pengolahan Tanah $=\frac{(L S x C F)}{K a x E x E}$

keterangan :

Jumlah Kebutuhan (Unit)

$\mathrm{LS}=$ Luas Sawah $(\mathrm{Ha})$

$\mathrm{CF}=$ Koefisien Faktor (asumsi nilainya 1)

$\mathrm{Ka}=$ Kapasitas Kerja $(\mathrm{Ha} / \mathrm{jam})$

$\mathrm{tE}=$ Hari Kerja Efektif (Hari)

$\mathrm{E}=\operatorname{Jam}$ Kerja Efektif (Jam/hari)

Jumlah Kebutuhan Alsintan Pascapanen $=\frac{(P x C F)}{K a x t E x E}$

keterangan :

Jumlah Kebutuhan (Unit)

$\mathrm{P}=$ Produksi Lahan Sawah $(\mathrm{Kg})$

$\mathrm{CF}=$ Koefisien Faktor (asumsi nilainya 1)

$\mathrm{Ka}=$ Kapasitas Kerja (Kg/jam)

$\mathrm{tE}=$ Hari Kerja Efektif (Hari)

$\mathrm{E}=$ Jam Kerja Efektif (Jam/hari) 


\section{HASIL DAN PEMBAHASAN}

\section{A. Gambaran Umum Hasil Penelitian}

Aplikasi Sistem Informasi Alsintan Pariaman Utara (SINTAN PARUT) terdiri dari 4 menu utama, yaitu: 1) alsintan; 2) lahan sawah; 3) informasi; dan 4) login admin. Aplikasi ini memanfaatkan database SQLite dengan menggunakan library room dan livedata untuk memperbaharui tampilan. Database SQLite dipilih karena aplikasi ini memiliki data terstruktur yang perlu diakses dan disimpan secaraterus-menerus serta sering ditelusuri dan diubah untuk tiap kali penambahan data ataupun ketika data yang telah dimasukkan rancu. Aplikasi SINTAN PARUT merupakan aplikasi yang berjalan menggunakan system operasi android dan didisain untuk smartphone. Aplikasi ini dapat berjalan pada android API 18 (Jelly Bean) dan maksimum android API 28 (Pie).

\section{B. Antarmuka Aplikasi}

Antarmuka aplikasi merupakan penggambaran bagaimana sebuah tampilan (interface) system aplikasi dibentuk. Aplikasi SINTAN PARUT dirancang dengan tampilan yang cukup sederhana, sehingga diharapkan mampu mempermudah pengguna dalam menjalankan aplikasi ini. Aplikasi ini memuat beberapa layout atau form, diantaranya:

\section{Tampilan Utama (Main Activity)}

Gambar 1 merupakan tampilan awal dari aplikasi pada saat aplikasi dibuka. Tampilan ini menampilkan menu-menu utama pada aplikasi SINTAN PARUT yaitu menu alsintan, lahan sawah, informasi dan login admin.

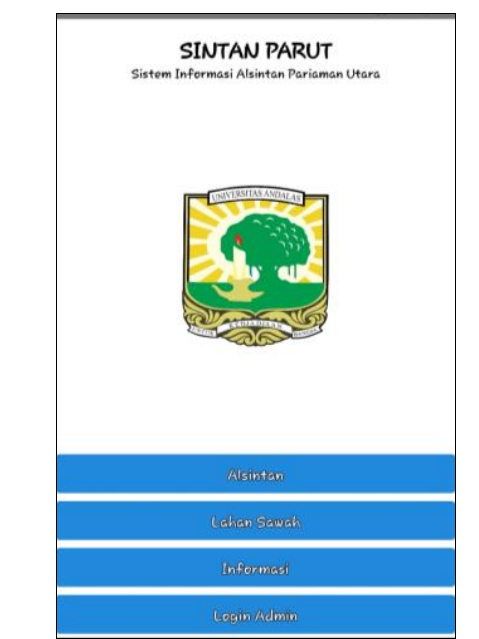

Gambar 1. Tampilan awal aplikasi

\section{Tampilan Menu Alsintan}

Gambar 2 merupakan tampilan lanjutan dari aplikasi. Tampilan ini memuat beberapa sub-sub menu yang terdiri dari menu alsintan pengolahan tanah, alsintan penanaman, alsintan pemeliharaan, alsintan pemanenan, alsintan pascapanen dan informasi bengkel pertanian. Masing-masing sub-sub menu memuat data alsintan pengolahan tanah mulai dari jumlah, merek, kapasitas kerja, kondisi alsintan sampai dengan hasil perhitungan kebutuhan ideal alsintan.

Pada menu ini pengguna aplikasi akan mendapatkan informasi terkait alsintan-alsintan apa saja yang digunakan pada pengolahan padi sawah mulai dari alsintan pengolahan tanah sampai dengan alsintan pascapanen dan termasuk juga informasi bengkel pertanian untuk perawatan mesin alsintan secara berkala.

Informasi yang akurat terkait dengan jumlah, merek, kapasitas kerja dan kondisi alsintan (baik atau rusak) akan menjadi sumber data utama untuk menentukan kebutuhan ideal alsintan pada Desadesa di Kecamatan Pariaman Utara. 


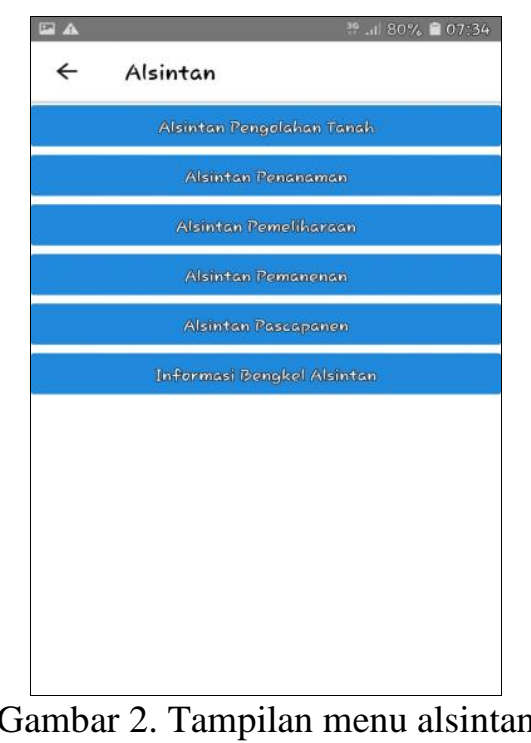

\section{Tampilan Sub Menu Alsintan Pengolahan Tanah}

Gambar 3 merupakan tampilan sub menu sub menu alsintan pengolahan tanah. Tampilan ini memuat data alsintan pengolahan tanah mulai dari jumlah, merek, kapasitas kerja, kondisi alsintan sampai dengan hasil perhitungan kebutuhan ideal alsintan.

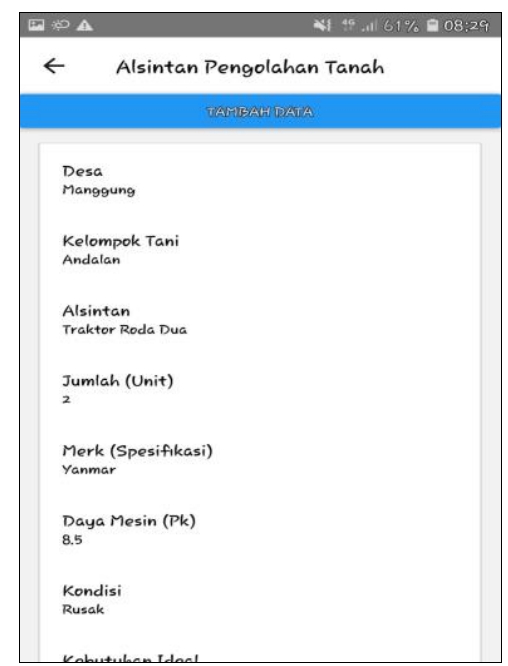

Gambar 3. Tampilan Sub Menu Alsintan Pengolahan Tanah

Pada menu ini pengguna aplikasi akan mendapatkan informasi terkait alsintan pengolahan tanah. Khusus alsintan pengolahan tanah data yang disajikan pada aplikasi ini terdiri dari 2 jenis alsintan pengolahan tanah yaitu traktor roda dua (hand tractor) dan hydro tiller. Penggunaan data 2 jenis alsintan tersebut didapatkan dari survei lapangan yang membuktikan bahwa alsintan pengolahan tanah yang secara umum digunakan oleh petani padi sawah pada Desa-desa di Kecamatan Pariaman Utara adalah traktor roda dua (hand tractor) dan hydro tiller.

Informasi yang akurat terkait dengan jumlah, merek, kapasitas kerja dan kondisi alsintan (baik atau rusak) pada alsintan pengolahan tanah akan menjadi sumber data utama untuk menentukan kebutuhan ideal alsintan pengolahan tanah pada lahan padi sawah di Desa-desa di Kecamatan Pariaman Utara.

\section{Tampilan Sub Menu Alsintan Pascapanen}

Gambar 4 merupakan tampilan sub menu alsintan pascapanen. Tampilan ini memuat data alsintan pascapanen mulai dari jumlah, merek, kapasitas kerja, kondisi alsintan sampai dengan hasil perhitungan kebutuhan ideal alsintan. 


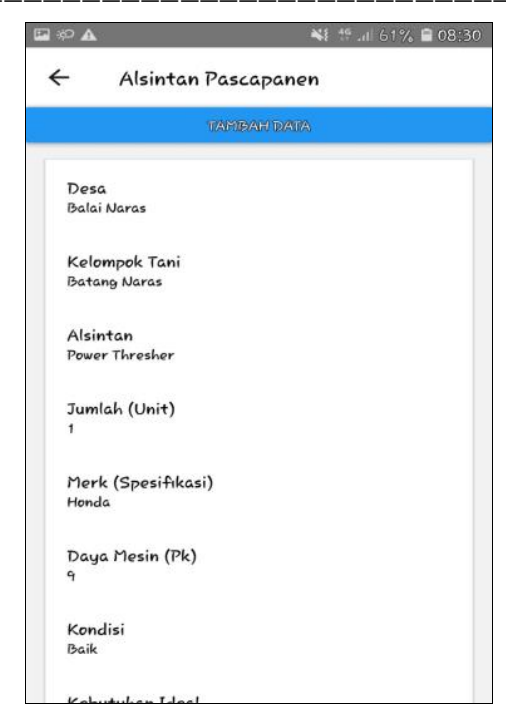

Gambar 4. Tampilan Sub Menu Alsintan Pascapanen

Pada menu ini pengguna aplikasi akan mendapatkan informasi terkait alsintan pascapanen. Khusus alsintan pascapanen data yang disajikan pada aplikasi ini terdiri dari 2 jenis alsintan pascapanen yaitu Power Threser dan Rice Milling Unit (RMU). Penggunaan data 2 jenis alsintan tersebut didapatkan dari survei lapangan yang membuktikan bahwa alsintan pascapanen yang secara umum digunakan oleh petani padi sawah pada Desa-desa di Kecamatan Pariaman Utara adalah Power Threser dan Rice Milling Unit (RMU).

Informasi yang akurat terkait dengan jumlah, merek, kapasitas kerja dan kondisi alsintan (baik atau rusak) pada alsintan pascapanen akan menjadi sumber data utama untuk menentukan kebutuhan ideal alsintan pascapanen pada lahan padi sawah di Desa-desa di Kecamatan Pariaman Utara.

\section{Tampilan Menu Lahan Sawah}

Gambar 5 merupakan tampilan lanjutan dari apliksi. Tampilan ini memuat beberapa sub-sub menu yang terdiri dari menu hamparan sawah, kelompok tani, sumber air, informasi alsintan yang digunakan, peta dan data spasial.

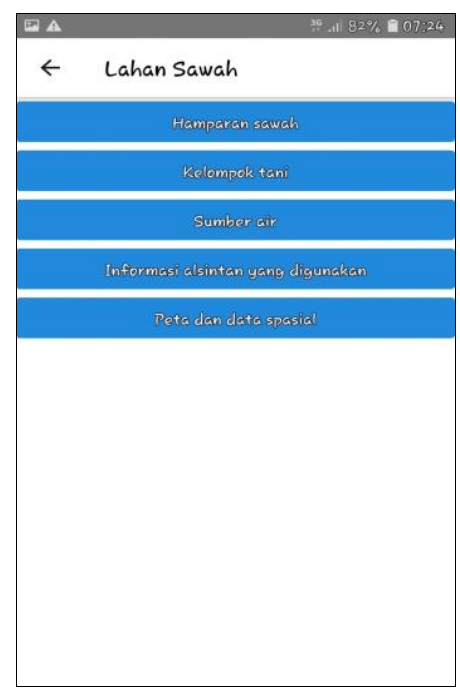

Gambar 5. Tampilan Menu Lahan Sawah

Sub menu hamparan sawah memuat data hamparan sawah mulai dari nama desa, nama hamparan sampai luas hamparan dalam satuan ha. Informasi yang disajikan pada sub menu hamparan sawah sangat penting diakses oleh pengguna aplikasi, berdasarkan luas hamparan beserta nama hamparannya maka pengguna bisa menjadikan sebagai data awal pada perhitungan kebutuhan alsintan ideal. 
Sub menu kelompok tani memuat data hamparan sawah mulai dari nama desa, nama kelompok tani, ketua, no. HP dan lokasi. Informasi yang disajikan pada sub menu kelompok tani juga sangat diperlukan untuk menentukan distribusi alsintan kepada kelompok tani berdasarkan luasan lahan sawah yang dimiliki oleh kelompok tani dan jumlah produksi padi yang dihasilkan oleh kelompok tani.

Sub menu sumber air memuat data sumber air mulai dari nama desa, sumber air dan kelompok tani. Informasi yang disajikan pada sub menu sumber air disajikan sebagai informasi apakah lahan sawah yang dikelola oleh kelompok tani masih tadah hujan, irigasi semi teknis maupun irigasi teknis. Informasi tersebut sangat penting bagi pengguna aplikasi untuk menentukan lahan sawah mana yang bisa dilakukan pengolahan tanah oleh alsintan pada saat pra tanam secara serentak berdasarkan sumber air lahan sawah tersebut.

Sub menu informasi alsintan yang digunakan memuat data nama desa, kelompok tani dan alsintan yang digunakan dalam satuan unit. Informasi yang disajikan pada sub menu informasi alasintan yang digunakan disajikan sebagai informasi kepada pengguna aplikasi bahwa jumlah dan jenis alsintan yang digunakan oleh kelompok tani pada Desa-desa di Kecamatan Pariaman Utara sudah ada pada database.

Sub menu peta dan data spasial memuat peta sebaran lahan, kelompok tani, sebaran alsintan, peta desa, peta jalan, peta sungai dan peta sintan parut. Informasi yang disajikan pada sub menu peta dan data spasial sangat penting disajikan kepada pengguna aplikasi untuk dapat menentukan titik lokasi lahan sawah dan distribusi alsintan, mulai dari alsintan pengolahan tanah sampai dengan alsintan pascapanen. Informasi dari sub menu peta dan data spasial juga diperlukan oleh pengguna aplikasi untuk mengetahui jarak antara satu desa dengan desa lainnya termasuk dengan jarak antara hamparan sawah dengan hamparan sawah lainnya untuk menentukan distribusi alsintan secara ideal.

\section{Tampilan Sub Menu Peta SINTAN PARUT}

Gambar 6 merupakan tampilan sub menu peta SINTAN PARUT. Tampilan ini memuat peta SINTAN PARUT dalam format pdf. Informasi yang disajikan pada sub menu peta SINTAN PARUT merupakan informasi secara akumulatif dengan menampilkan data spasial secara detail di Kecamatan Pariaman Utara diantaranya yaitu: peta sebaran lahan, peta kelompok tani, peta sebaran alsintan, peta desa, peta jalan dan peta sungai. Peta SINTAN PARUT merupakan informasi yang paling puncak untuk pengguna aplikasi dalam menentukan distribusi alsintan secara ideal.

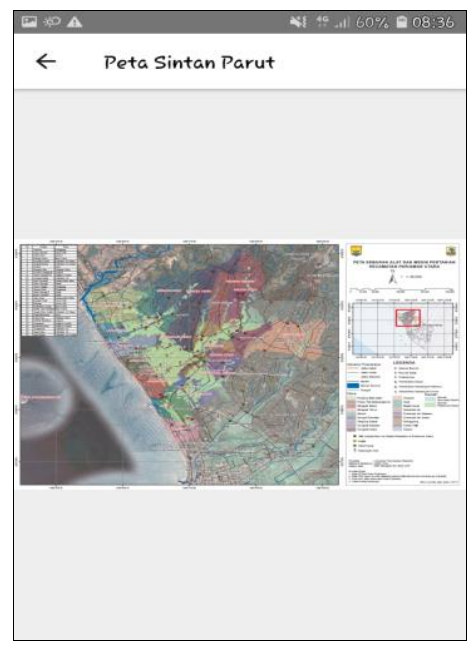

\section{Gambar 6. Tampilan Sub Menu Peta SINTAN PARUT}

\section{Tampilan Menu Login Admin}

Gambar 7 merupakan tampilan lanjutan dari apliksi. Tampilan ini memuat beberapa sub-sub menu yang terdiri dari menu login admin dan login super admin. Untuk menjaga agar data-data yang tersedia pada aplikasi dapat update secara terus-menerus maka diperlukan menu Login Admin. Seorang admin ataupun pihak yang terkait dalam pengembangan sistem informasi ini dapat melakukan update informasi dari meni ini, agar informasi yang disampaikan akurta dan tepat pada sistem tersebut sehingga dapat bekerja sesuai dengan tujuan dan kegunaannya. 


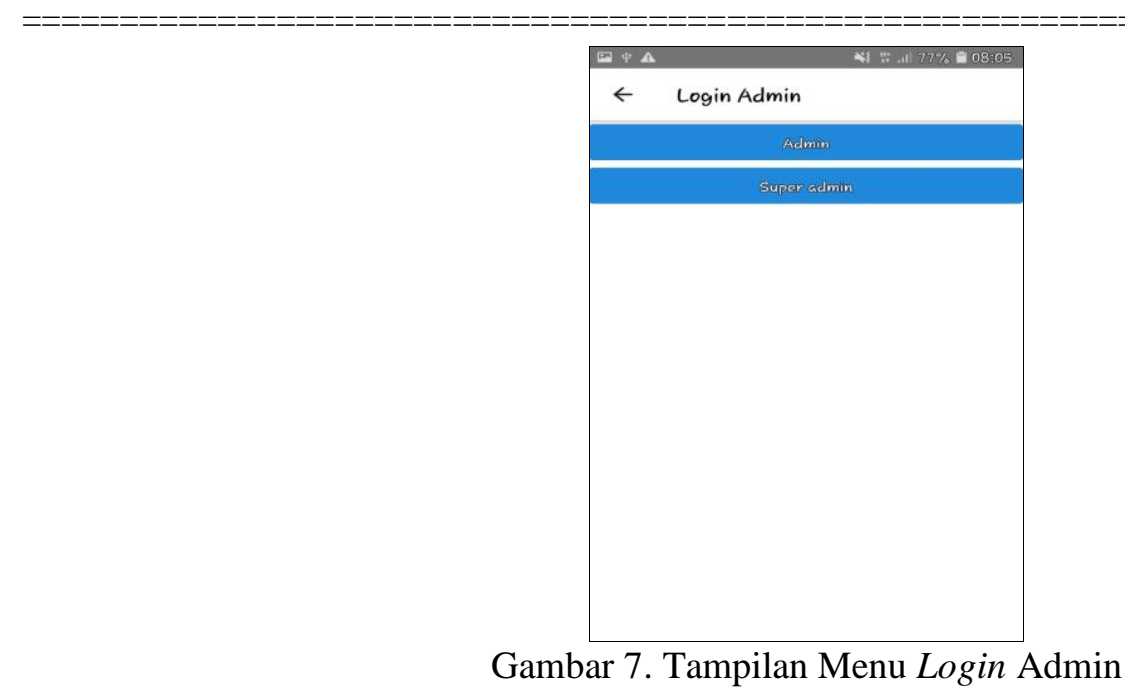

Menu login admin ini hanya bisa diakses oleh administrator sistem dengan memasukkan username dan password. Menu ini dirancang khusus bagi admin, dimana pada menu ini digunakan untuk mengubah, menghapus dan menambah isi data. Perrmintaan login dirancang untuk menjaga keamanan data-data yang tersimpan pada basis data sehingga tidak sembarang orang/pengguna aplikasi yang bisa masuk ke bagian admin. Untuk lebih menjaga keamanan database maka diperlukan lagi login super admin. Super admin berfungsi untuk membuat username dan password bagi admin, selanjutnya super admin juga memiliki jangkaun yang sangat luas untuk melihat riwayat edit, hapus dan tambah yang dilakukan oleh admin pada sistem aplikasi.

\section{Tampilan Menu Informasi}

Gambar 8 merupakan tampilan lanjutan dari aplikasi. Tampilan ini memuat beberapa sub-sub menu yang terdiri dari menu informasi penulis, aplikasi pembuka peta dan jumlah pengunjung. Informasi yang disajikan pada menu informasi merupakan tambahan data atau informasi bagi pengguna aplikasi dalam menentukan distribusi dan kebutuhan alsintan secara ideal di Kecamatan Pariaman Utara.

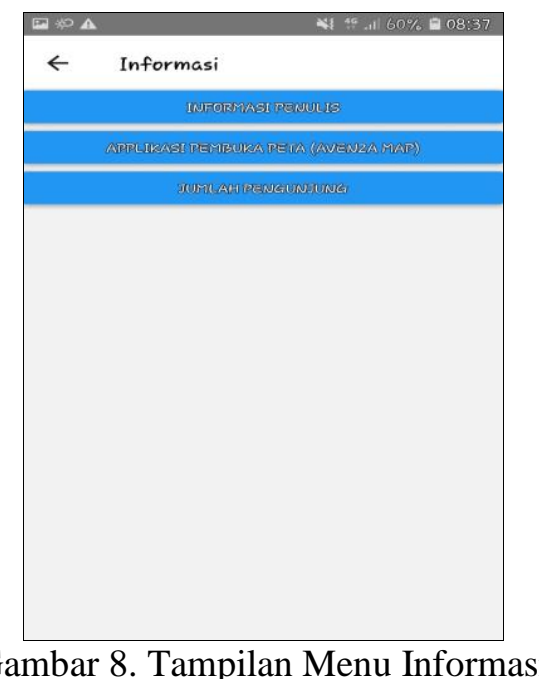

Pengguna aplikasi akan bisa mengetahui biodata dari penulis/perancang aplikasi, kemudian aplikasi pembuka peta untuk akses lokasi lahan sawah secara online melalui GPS dan Satelit. Jumlah kunjungan/akses pada aplikasi juga akan memberikan nilai tambahan tersendiri pada aplikasi yang digunakan, semakin banyak jumlah pengunjung maka data tersebut menunjukkan bahwa aplikasi yang digunakan semakin diminati karena kemudahan untuk diakses, menarik dan menyajikan informasi yang akurat dan update tentang distribusi dan kebutuhan alsintan yang ideal melalui sistem informasi berbasis aplikasi android di Kecamatan Pariaman Utara. 


\section{Analisis Kebutuhan Ideal Alsintan}

1. Analisis Kebutuhan Ideal Alsintan Pengolahan Tanah

Berdasarkan Tabel 1 dapat dianalisis kebutuhan ideal alsintan pengolahan tanah bahwa dari 17

Desa di Kecamatan Pariaman Utara terdapat 41,18 \% mengalami kekurangan alsintan, sedangkan $41,18 \%$ mengalami kelebihan alsintan dan hanya 17,64\% memiliki kebutuhan alsintan yang ideal.

Tabel 1. Hasil Analisis Kebutuhan Ideal Alsintan Pengolahan Tanah

\begin{tabular}{lcccl}
\hline \multicolumn{1}{c}{ Desa } & Luas Tanam (ha) & $\begin{array}{c}\text { Jumlah } \\
\text { Kebutuhan (Unit) }\end{array}$ & $\begin{array}{c}\text { Ketersediaan } \\
\text { (Unit) }\end{array}$ & Hasil Analisis \\
\hline Ampalu & 12 & 2 & 1 & Kurang \\
Apar & 14 & 2 & 0 & Kurang \\
Balai Naras & 39 & 4 & 2 & Kurang \\
Cubadak Air & 59 & 6 & 8 & Berlebih \\
Cubadak Air Selatan & 15 & 2 & 6 & Berlebih \\
Cubadak Air Utara & 35 & 4 & 6 & Berlebih \\
Manggung & 52 & 5 & 8 & Berlebih \\
Naras Hilir & 37 & 4 & 4 & Ideal \\
Naras I & 8 & 1 & 3 & Berlebih \\
Padang Birik Birik & 5 & 1 & 1 & Ideal \\
Sikapak Barat & 43 & 5 & 4 & Kurang \\
Sikapak Timur & 8 & 1 & 2 & Berlebih \\
Sintuk & 24 & 3 & 6 & Berlebih \\
Sei Rumbai & 5 & 1 & 1 & Ideal \\
Tanjung Sabar & 48 & 5 & 4 & Kurang \\
Tungkal Selatan & 48 & 5 & 4 & Kurang \\
Tungkal Utara & 2 & 1 & 0 & Kurang \\
\hline
\end{tabular}

Kebutuhan ideal alsintan pengolahan tanah dipengaruhi oleh luas hamparan sawah yang akan diolah oleh alsintan, jarak antara hamparan sawah yang satu dengan yang lainnya. Selanjutnya berdasarkan analisis dan survei di lapangan ditemukan fakta lain bahwa banyak petani yang mengolah lahan sawah mereka memakai jasa alsintan pengolahan tanah dari saudara/kerabat terdekat yang bukan berdomisili pada lokasi hamparan sawah yang diolah sehingga kebiasaan seperti ini akan berpengaruh sangat besar pada distribusi alsintan pengolahan tanah secara ideal. Dampak dari kebiasaan pada petani tersebut dibuktikan dengan hasil analisis yang menunjukkan bahwa hanya $17,64 \%$ memiliki kebutuhan alsintan yang ideal. Jumlah tersebut tentu masih sangat rendah dan perlu ditingkatkan agar distribusi dan kebutuhan ideal alsintan menggunakan sistem informasi berbasis aplikasi android di Kecamatan Pariaman Utara bisa tercapai.

\section{Analisis Kebutuhan Ideal Alsintan Pascapanen}

Berdasarkan Tabel 2 dapat dianalisis kebutuhan ideal alsintan pascapanen dari 17 Desa di Kecamatan Pariaman Utara terdapat 29,42 \% mengalami kekurangan alsintan, sedangkan 17,64 \% mengalami kelebihan alsintan dan 52,94\% memiliki kebutuhan alsintan yang ideal. Kebutuhan ideal alsintan pascapanen berdasarkan hasil analisis sudah cukup baik karena sudah mencapai nilai 52,94\%, berarti lebih dari setengah Desa-desa di Kecamatan Pariaman Utara sudah terpenuhi kebutuhan alsintan pascapanen secara ideal.

Berdasarkan analisis dan survei di lapangan ditemukan fakta lain bahwa masih ada desa yang belum tersedia alsintan pascapanen karena jarak tempuh antara satu hamparan sawah dengan hamparan sawah yang lainnya berdekatan, sehingga pemilik/penyedia jasa alsintan pengolahan pascapanen cenderung menempatkan alsintannya pada daerahnya berdomisili, disamping itu secara perhitungan tekno-ekonomi apabila menempatkan alsintan pascapanen pada Desa-desa yang tidak potensial maka pemilik/penyedia jasa alsintan akan mengalami kerugian sehingga kondisi yang ada dilapangan tersebut akan sangat berpengaruh pada distribusi alsintan pascapanen yang tidak ideal. Dampak dari kegiatan penyedia/pemilik alsintan tersebut dibuktikan dengan hasil analisis yang menunjukkan bahwa masih ada sejumlah $29,42 \%$ mengalami kekurangan alsintan. Jumlah tersebut tentu masih tinggi dan perlu diturunkan agar distribusi dan kebutuhan ideal alsintan menggunakan sistem informasi berbasis aplikasi android di Kecamatan Pariaman Utara bisa tercapai. 


\begin{tabular}{|c|c|c|c|c|c|}
\hline Desa & $\begin{array}{l}\text { Produksi Padi } \\
\qquad(\mathrm{Kg})\end{array}$ & $\begin{array}{l}\text { Jenis Alsintan } \\
\text { (Unit) }\end{array}$ & $\begin{array}{l}\text { Jumlah } \\
\text { Kebutuhan } \\
\text { (Unit) }\end{array}$ & $\begin{array}{l}\text { Ketersediaan } \\
\quad \text { (Unit) }\end{array}$ & $\begin{array}{c}\text { Hasil } \\
\text { Analisis }\end{array}$ \\
\hline Ampalu & $18.295,00$ & Power Thresher & 1 & 1 & Ideal \\
\hline Apar & $21.344,17$ & - & - & - & Kurang \\
\hline Balai Naras & $59.458,75$ & Power Thresher & 1 & 2 & Berlebih \\
\hline Balai Naras & $59.458,75$ & Power Thresher & 1 & 1 & Ideal \\
\hline Cubadak Air & $89.950,42$ & Power Thresher & 2 & 2 & Ideal \\
\hline Cubadak Air & $89.950,42$ & Rice Milling Unit & 1 & 2 & Berlebih \\
\hline Cubadak Air Selatan & $22.868,75$ & Power Thresher & 1 & 1 & Ideal \\
\hline Cubadak Air Utara & $53.360,42$ & - & - & - & Kurang \\
\hline Manggung & $79.278,33$ & Power Thresher & 2 & 1 & Kurang \\
\hline Naras Hilir & $56.409,58$ & Power Thresher & 1 & 1 & Ideal \\
\hline Naras I & $12.196,67$ & Power Thresher & 1 & 1 & Ideal \\
\hline Padang Birik Birik & $7.622,97$ & - & - & - & Kurang \\
\hline Sikapak Barat & $65.557,08$ & Power Thresher & 2 & 2 & Ideal \\
\hline Sikapak Timur & $12.196,67$ & Rice Milling Unit & 1 & 1 & Ideal \\
\hline Sintuk & $36.590,00$ & Rice Milling Unit & 1 & 2 & Berlebih \\
\hline Sei Rumbai & $7.622,92$ & Power Thresher & 1 & 1 & Ideal \\
\hline Tanjung Sabar & $73.180,00$ & Power Thresher & 2 & 1 & Kurang \\
\hline Tungkal Selatan & $73.180,00$ & Power Thresher & 2 & 2 & Ideal \\
\hline Tungkal Selatan & $73.180,00$ & Rice Milling Unit & 1 & 3 & Kurang \\
\hline Tungkal Utara & $3.049,17$ & - & - & - & Kurang \\
\hline
\end{tabular}

\section{KESIMPULAN}

Aplikasi Sistem Informasi Alsintan Pariaman Utara (SINTAN PARUT) telah berhasil dirancang dan dapat berjalan pada android API 18 (Jelly Bean) sampai android API 28 (Pie) serta bisa diakses secara mobile dan online. Aplikasi Sistem Informasi Alsintan Pariaman Utara (SINTAN PARUT) juga menampilkan data perhitungan kebutuhan ideal alsintan di Kecamatan Pariaman Utara yang menunjukkan bahwa sebagian besar distribusi alsintan sudah ideal dan berlebih, walaupun masih ada Desa yang kekurangan alsintan. Kebutuhan ideal alsintan tersebut masih bisa diperbarui datanya sesuai dengan kondisi terkini.

\section{DAFTAR PUSTAKA}

[BPS] Badan Pusat Statistik Kota Pariaman. 2019. Kota Pariaman Dalam Angka 2019.

[BPS] Badan Pusat Statistik Provinsi Sumatera Barat 2018. Provinsi Sumatera Barat Dalam Angka 2018.

Fandra, Ilhami. 2018. Audit Lahan Pertanian Sawah Untuk Menunjang Ketahanan Pangan di Kota Pariaman [Skripsi]. Padang (ID) : Fakultas Teknologi Pertanian. Universitas Andalas.

Indriawardhana, Prawesa Adi Kumara. 2019. Rancang Bangun Aplikasi Penyedia Jasa dalam Sistem Jasa Alsintan Terpadu Online Berbasis Android [Skripsi]. Bogor (ID): Institut Pertanian Bogor.

Jamalus. 2016. Mekanisasi, Peran dan pentingnya dalam pembangunan Pertanian [Internet]. http://www.sumbarprov.go.id/details/news/6664. [Diakses tanggal 2 September 2019. Pukul 10:00 WIB].

Putri, Feni Mardila., Hamdi Nur., Rini Asmarianti. 2019. Kajian Tipologi Alih Fungsi Lahan Sawah di Kota Pariaman [Jurnal]. Fakultas Teknik Sipil dan Perencanaan. Universitas Bung Hatta. Vol.1 No.3. http://ejurnal.bunghatta.ac.id/

StatCounter. 2019. Market share held by mobile operating systems in Indonesia from January 2019 to August $2019 \quad$ [Internet] https://gs.statcounter.com/vendor-marketshare/mobile/worldwide/\#monthly-201901-201908-bar [Diakses tanggal 2 September 2019. Pukul 13:00 WIB]. 